ISSN 0976 - 6995 (Print)

ISSN 0976 - 7002 (Online)

Volume 5, Issue 1, January - April (2014), pp. 01-11

(C) IAEME: https://iaeme.com/Home/journal/IJDMT

https://doi.org/10.34218/IJDMT.5.1.2014.30320140501001

IJDMT

(C) I A E M E

\title{
CONSTANT SPEED ENGINE CONROD SOFT VALIDATION \& OPTIMIZATION
}

\author{
Anand. D. Dantale ${ }^{1}$, Ashok J. Keche ${ }^{2}$ \\ ${ }^{\mathbf{1}}$ Mechanical Engineering Department, MIT, Aurangabad (M.S), India \\ ${ }^{2}$ Associate Professor, Mechanical Engineering Department, MIT, Aurangabad (M.S), India
}

\begin{abstract}
The constant speed four stroke reciprocating engine Connecting rod is subjected to variable loading when Engine is in operating condition. Proper optimization of connecting rod is critical for the engine Performance, vibration level \& balancing of overall engine. The stresses in Connecting rod are not constant during its operating condition. The stress varies in one complete cycle. The connecting rod traditionally were designed and analyzed under Static axial loading condition. The Quasi-dynamic approach has a considerable effect in design optimization of connecting rod. The finite element analysis of four stroke Diesel engine is considered. Structural systems of connecting rod can be easily analyzed using Finite Element techniques. So firstly a proper a CAD model is developed Pro/E Wildfire 4.0. Then the Finite element analysis is done to determine the Von Mises stresses in the existing connecting rod for the given loading conditions using Finite Element Analysis software ANSYS. The optimization of conrod is done based on the results and validated.
\end{abstract}

Keyword : Constant Speed, Soft Validation, Optimization, Conrod \& Finite Element Analysis.

\section{INTRODUCTION}

A connecting rod undergoes a very complex motion, and is subjected to a complex, time varying axial and bending loads. The details of the analytical vector approach to determine the inertia loads and its reactions are used for determining the inertia loads. Such stress analysis in true operating loads is critical to any durability or optimization study of a 
International Journal of Design and Manufacturing Technology (IJDMT), ISSN 0976 - 6995(Print), ISSN 0976 - 7002(Online) Volume 5, Issue 1, January - April (2014), pp. 01-11 @ IAEME

connecting rod. Normally in static analysis, the loads acting at the Small ends \& big end of the connecting rod are equal in magnitude and are in static equilibrium. In case of quasidynamic analysis, the loads at the two ends may not be equal. It is equal only when at any instant in time, the inertia load resulting from both translational and angular velocity with acceleration are considered are in equilibrium. The quasi-dynamic analyses are repeated based on time-varying dynamic input data. The analysis is referred to as 'quasi-dynamic'. The dynamic load analysis is used for fatigue behavior of the connecting rod. The bending moment is derived from bending stress having a function of load at the CG normal to the connecting rod longitudinal axis plus the angular and linear acceleration components normal to this axis. Variation of each of these three quantities over one complete rotation is identical to the variation in two revolutions of crankshaft. The axial load variation, needs to be considered over the two revolution of crankshaft as in case of Four stroke Engines the power stoke as a high impact of gas load. The connecting rod considered is of diesel Engine. The actual Pressure Variations on the piston is measured in combustion chamber over number of engine cycles.

\section{LITERATURE REVIEW}

Yoo et al. [1] performed shape optimization of an engine connecting rod using variation equations of elasticity, and an ad joint variable technique to calculate shape design sensitivities of stress. The results were then used in an iterative optimization algorithm to numerically solve for an optimal design solution. Serag et al. [2] developed approximate mathematical formulae to define connecting rod weight and cost as objective functions as well as constraints. The optimization was achieved using a geometric programming technique. Sarihan and Song [3] optimized the wrist pin end of an engine connecting rod with an interference fit. The load cycle that was used consisted of compressive gas load corresponding to a maximum torque and a tensile load corresponding to maximum inertia load. The modified Goodman equation with alternating and mean octahedral shear stress was used for fatigue analysis. Pai [4] presented an approach to optimize the shape of a connecting rod subjected to a load cycle which consisted of the inertia load deducted from gas load as one extreme and peak inertia load exerted by the piston assembly mass as the other extreme. A finite element routine was first used to calculate the displacements and stresses in the rod, which were then used in another routine to calculate the total life. Fatigue life was defined as the sum of crack initiation and crack growth lives, with crack growth life obtained using fracture mechanics. Change in the material, resulting in a significant reduction in machining cost, was the key factor in cost reduction. As a result, in this optimization problem the cost and the weight were dealt with separately. The structural factors considered for weight reduction during the optimization include the buckling load factor, stresses under the loads, bending stiffness, and axial stiffness. Cost reduction is achieved by using C-70 steel, which is fracture crackable.

Sonsino and Esper [5] discussed the fatigue design of sintered connecting rods. They did not perform optimization of the connecting rod. They performed preliminary FEA followed by production of a prototype. Fatigue tests and experimental stress analysis were performed on this prototype. In order to verify that the design was safe under fatigue, they computed the allowable stress amplitude at critical locations, taking the R-ratio, the stress concentration, and statistical safety factors into account, and ensured that maximum stress amplitudes were below the allowable stress amplitude. Serag et al [6] developed are approximate mathematical formulae to define connecting rod weight and cost as objective 
International Journal of Design and Manufacturing Technology (IJDMT), ISSN 0976 - 6995(Print), ISSN 0976 - 7002(Online) Volume 5, Issue 1, January - April (2014), pp. 01-11 @ IAEME

functions and also the constraints. The optimization was achieved using a Geometric Programming technique. The compression stress, the bearing pressure at the crank and the piston pin ends were constrained.

\section{OBJECTIVES}

In present study the multi cylinder diesel engine connecting rod is considered for optimization. The objectives involved are:

1. To model a connecting rod using Pro/E

2. To perform quasi-dynamic finite element analysis.

3. To identify the area where optimization of weight can be performed without having any effect on safety margins.

\section{MODELING OF CONNECTING ROD USING PRO-E 4.0}

The 3D model is done using Pro/E software. The surface modelling is used for modeling. of connecting rod. The model is prepared using parametric design approach. Refer Fig 1. For simplification, the flash along the entire connecting rod length, the oil hole and the chamfers at both the ends of connecting rod. were removed in order to reduce the model size. The flash in the original model was of about $1 \mathrm{~mm}$ thickness and the hole was of diameter 6 $\mathrm{mm}$. It can be expected that these simplification would lead to substantial savings in the solution time, without compromising on the accuracy of the solution. The bolt holes were not eliminated. The connecting rod is symmetrical only at the small end and shank area whereas the crank end is not symmetrical in both the width and thickness directions. The connecting rod mass as measured on a weighing scale was found to be $5.00 \mathrm{~kg}$ whereas the mass of the solid model after simplification and meshing was $4.95 \mathrm{~kg}$. Thus the two masses, namely the actual mass of the con rod and that obtained from the simplified model, differ by less than $1 \%$, indicating the accuracy of the model used for analysis.

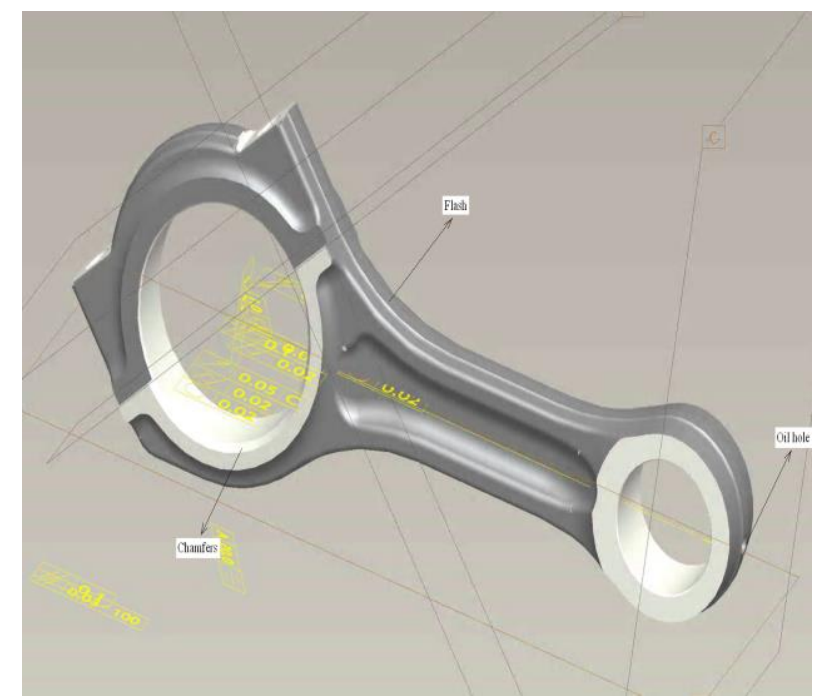

Fig.1. 3D model of connecting rod 
International Journal of Design and Manufacturing Technology (IJDMT), ISSN 0976 - 6995(Print), ISSN 0976 - 7002(Online) Volume 5, Issue 1, January - April (2014), pp. 01-11 @ IAEME

\section{TO PERFORM QUASI-DYNAMIC FINITE ELEMENT ANALYSIS}

The Engine \& conrod specification is as follows

Table 1.1 Engine Specifications

\begin{tabular}{|l|c|}
\hline Engine type & V- type, stationary \\
\hline Power & $1200 \mathrm{HP}$ \\
\hline Number of cylinders & 16 \\
\hline Engine speed & $1500 \mathrm{rpm}$ \\
\hline Material & $82 \mathrm{CrMoS} 4 \mathrm{~N}$ \\
\hline Ultimate strength & $640 \mathrm{Mpa}$ \\
\hline Yield strength & $2.1 \mathrm{e}^{5} \mathrm{Mpa}$ \\
\hline Module of Elasticity & 0.3 \\
\hline Poisson's ratio & $7850 \mathrm{~kg} / \mathrm{m}^{3}$ \\
\hline Density & $5.0 \mathrm{~kg}$ \\
\hline Mass of con rod & $275 \mathrm{~mm}$ \\
\hline Length (c-c) & $103 \mathrm{~mm}$ \\
\hline Dia. of big end & $50 \mathrm{~mm}$ \\
\hline Dia. of small end & \\
\hline
\end{tabular}

The components of forces acting on the connecting rod ends in the $\mathrm{X}$ and $\mathrm{Y}$ directions are obtained; they can be resolved into components along the connecting rod length and normal to it. The components of the inertia load acting at the centre of gravity can also be resolved into similar components. Depending upon the magnitudes of the forces acting on the connecting rod a few positions of the crank were selected, so that the FEA could be performed at only the selected crank positions. The connecting rod as it undergoes a complete cycle consists of two components, the bending stress component and the axial stress component. The bending stress depends on the bending moment, which is a function of the load at the C.G. normal to the connecting rod axis, as well as the components of the angular acceleration and linear acceleration normal to the connecting rod axis. The variation of each of these three quantities over first revolution of crankshaft is similar to the second revolution of crankshaft in case of four stoke engine. The axial load variation does not follow this pattern. One cycle of axial load variation consists of the entire two revolution of crank angle. This is due to the variation in the gas load, one cycle of which consists of two revolution of crankshaft.

The meshing was carried out using Hyper Mesh software, which automatically decides the size of mesh in different areas of the model. The finite element mesh was generated using parabolic tetrahedral elements $4 \mathrm{~mm}$ (42184 elements)

\subsection{Load application and boundary conditions}

The forces acting on the two ends of the connecting rod were calculated for different angular positions of the crank. The crank positions, for which the axial (tensile / compressive) load acting on the con rod was maximum. Maximum tensile load position and the maximum compressive load position. 
International Journal of Design and Manufacturing Technology (IJDMT), ISSN 0976 - 6995(Print), ISSN 0976 - 7002(Online) Volume 5, Issue 1, January - April (2014), pp. 01-11 @ IAEME

\subsubsection{Maximum Tensile loading of the connecting rod}

This corresponds to the crank position of 3600 . For the tensile loading, both the ends of the conrod were assumed to be subjected to a sinusoidal distributed load over the contact surface area spanning over 1800, as shown in Maximum compressive loading of the con rod: This corresponds to the crank angle position of $0 \circ$ For this case the recommended load distribution is a uniform load distribution acting over a contact area of spanning over 1200.

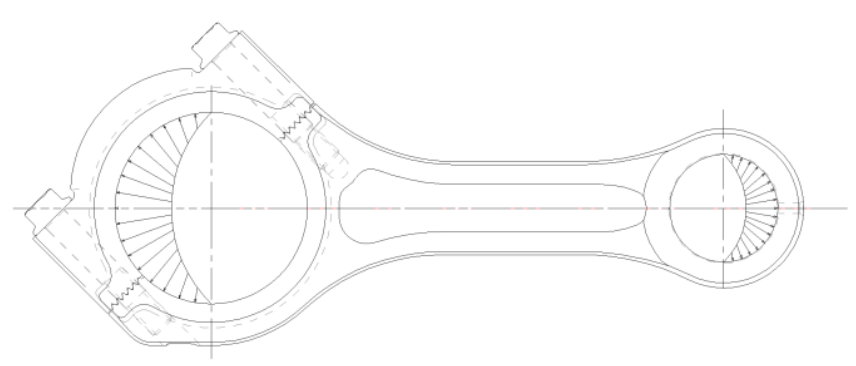

Fig.2. Tensile loading of the connecting rod

A. Maximum Compressive Loading of the conrod

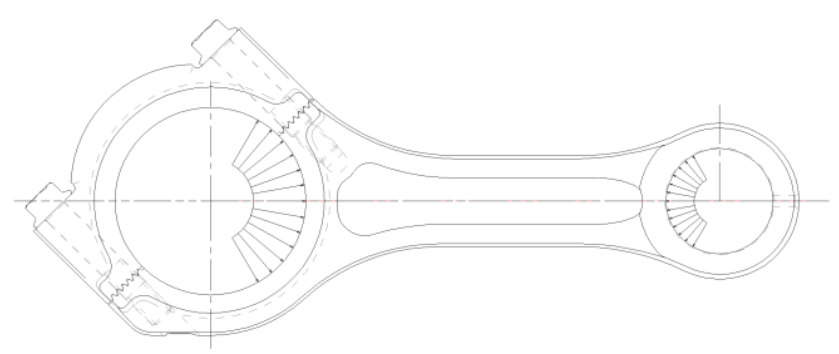

Fig .3. Compressive loading of the connecting rod

The maximum compressive load acts on the $\operatorname{con}$ rod at $\theta=50$, and at this position the angle between the resultant and axial forces is very small. Therefore, the normal force was ignored and only the axial compressive force was assumed to be acting on the con rod. The force was applied as a uniformly distributed load over $120^{\circ}$ of contact area, on the piston end, and all the nodes of $120^{\circ}$ of contact area of the crank were treated as fixed, i.e. all their degrees of freedom were set to zero. See Fig 4.

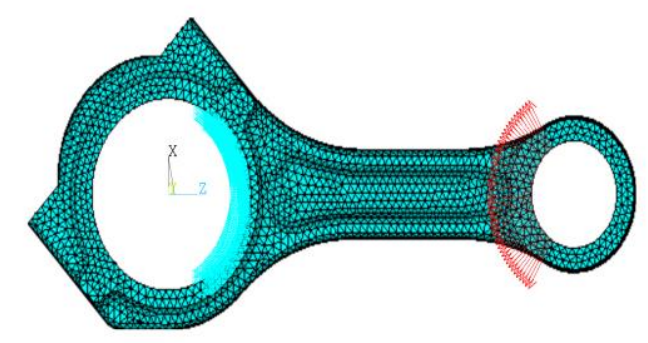

Fig.4. Maximum compressive force applied at the small end, fixed crank end. 
International Journal of Design and Manufacturing Technology (IJDMT), ISSN 0976 - 6995(Print), ISSN 0976 - 7002(Online) Volume 5, Issue 1, January - April (2014), pp. 01-11 @ IAEME

The net axial force (along the line through centers) for the compressive load condition is $232600 \mathrm{~N}$ and to have this value of net axial force, one has to apply a force of $286000 \mathrm{~N}$ in a uniformly distributed manner, which wills over 1200.

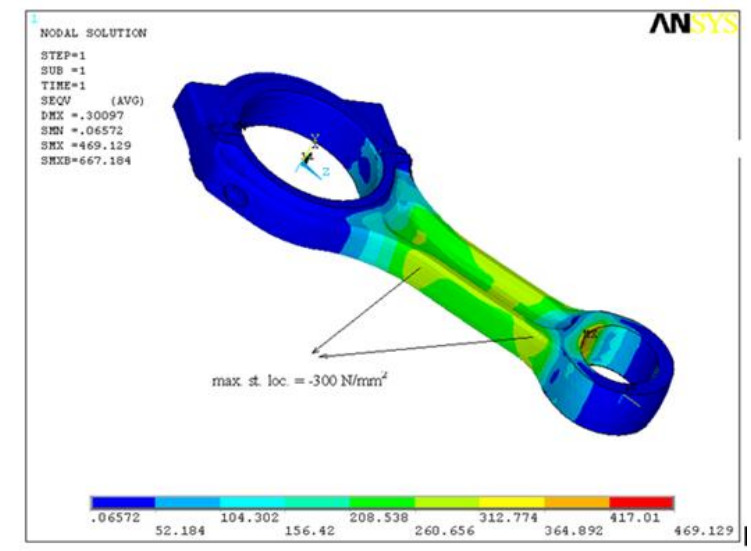

Fig.5. FEA results for maximum compressive load (force applied on the small end)

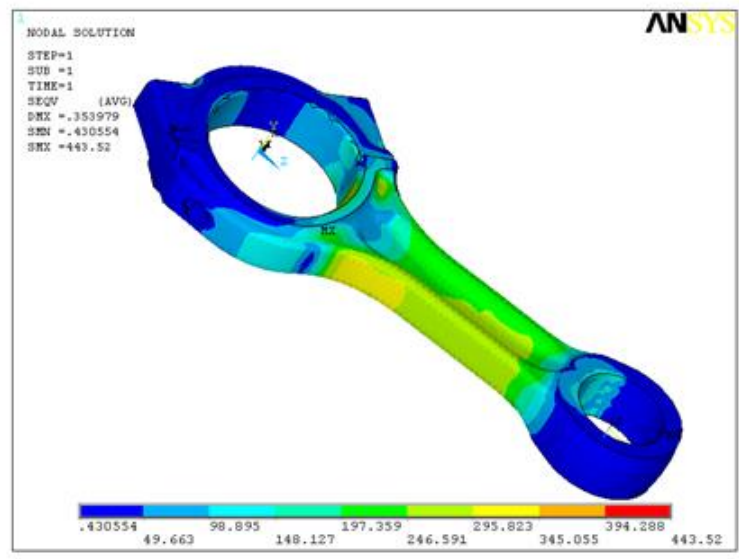

Fig. 6. FEA results for maximum compressive load (force applied on the big end)

With this load, the static FE analysis was carried out using the ANSYS software. The Von Mises stresses at different locations of the connecting rod are shown. The maximum stress is developed in the shank area between the big and small ends. The maximum stress is seen to be approximately $300 \mathrm{~N} / \mathrm{mm} 2$. A stress value of about $400 \mathrm{~N} / \mathrm{mm} 2$, is seen at the small end, but it is not important as this value is due to the high localized value of the applied force and can therefore be ignored.

\subsubsection{Analysis under Maximum Tensile Load}

The maximum tensile load acts at the crank angle of 3600 at which the gas pressure is minimum and the inertia forces due to the acceleration of connecting rod and piston give to rise to the tensile loading of the connecting rod. In high speed engines, the tensile force can be comparable to or more than the gas force. The tensile load should be applied as a force distributed sinusoidal over 1800 of contact area of the small end The value of the maximum tensile force is $19000 \mathrm{~N}$. Figure 7 shows how the forces and constraints are applied on the 
International Journal of Design and Manufacturing Technology (IJDMT), ISSN 0976 - 6995(Print), ISSN 0976 - 7002(Online) Volume 5, Issue 1, January - April (2014), pp. 01-11 @ IAEME

connecting rod. Because the tensile load is less important in this work, the distribution of the force was simplified and treated as uniform.

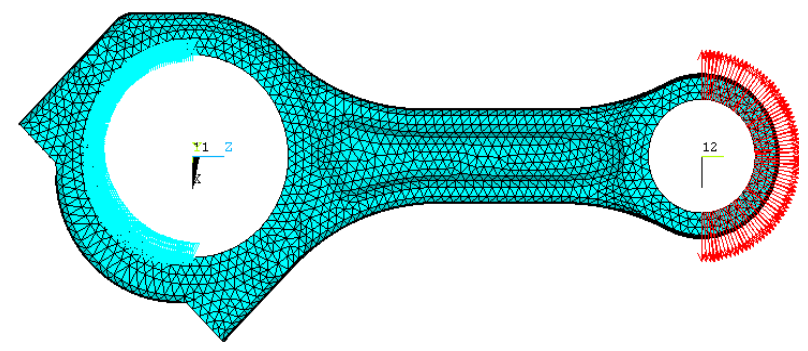

Fig.7. Application of force and constraints for maximum tensile load

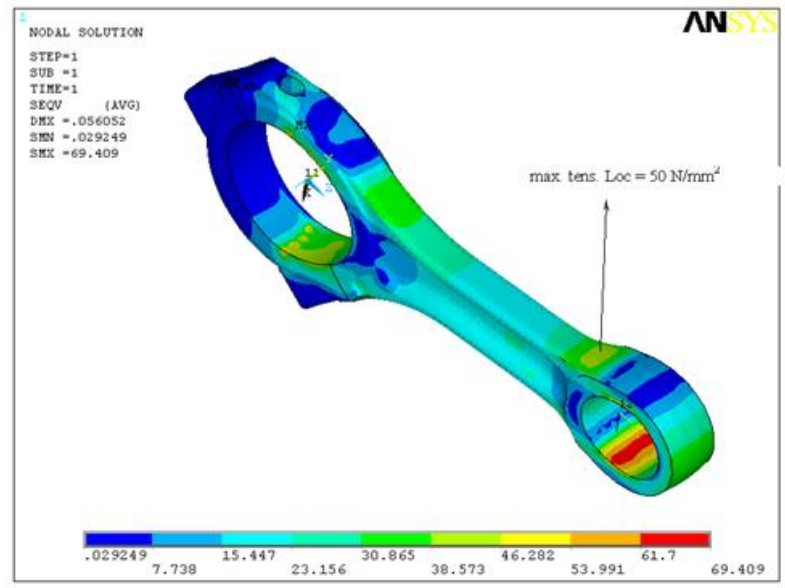

Fig.8. FEA result for maximum tensile loading force of $19 \mathrm{KN}$ (force applied on the small end)

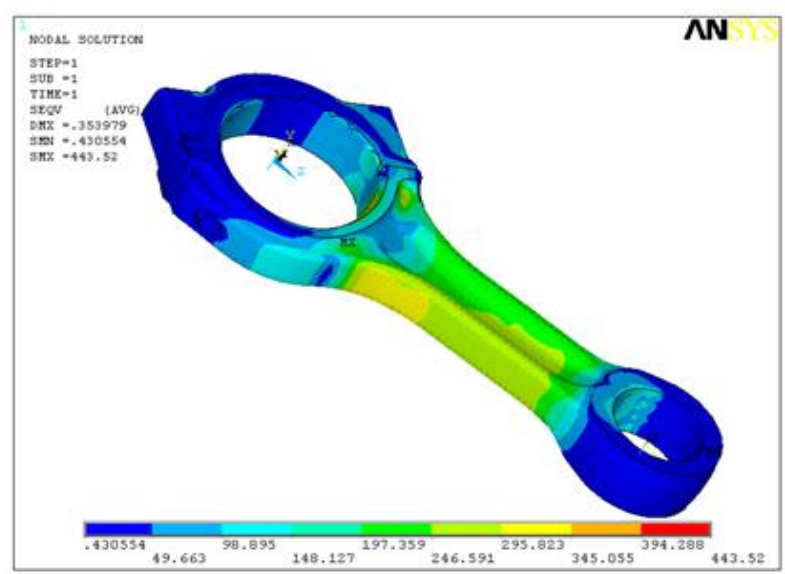

Fig. 9. FEA results for maximum compressive load (force applied on the big end) 
International Journal of Design and Manufacturing Technology (IJDMT), ISSN 0976 - 6995(Print), ISSN 0976 - 7002(Online) Volume 5, Issue 1, January - April (2014), pp. 01-11 @ IAEME

\section{RESULT \& DISCUSSION OF QUASI-DYNAMIC FINITE ELEMENT ANALYSIS}

\subsection{Finite Element Analysis}

The FEA results indicate the stresses at locations (shown in Figure 11) of the connecting rod. The greater stresses at any location from the results of FEA (compressive loading $(232.6 \mathrm{KN})$ or tensile loading $(19 \mathrm{KN})$ have been considered. The results are shown in table 1 the Von Mises stresses of different locations are shown in Figure 10. This figure shows stresses at locations 1 to 13 . It can be seen that the stress level at locations 2, 3,4,11, 12 and 13 are quite low, these locations lying in the piston end region and crank end region of the connecting rod. The locations within the shank area stresses are seen higher at locations 6 to 9 . The regions connecting rod which is less stressed can provide a scope for removal of material and thus weight optimization is possible.

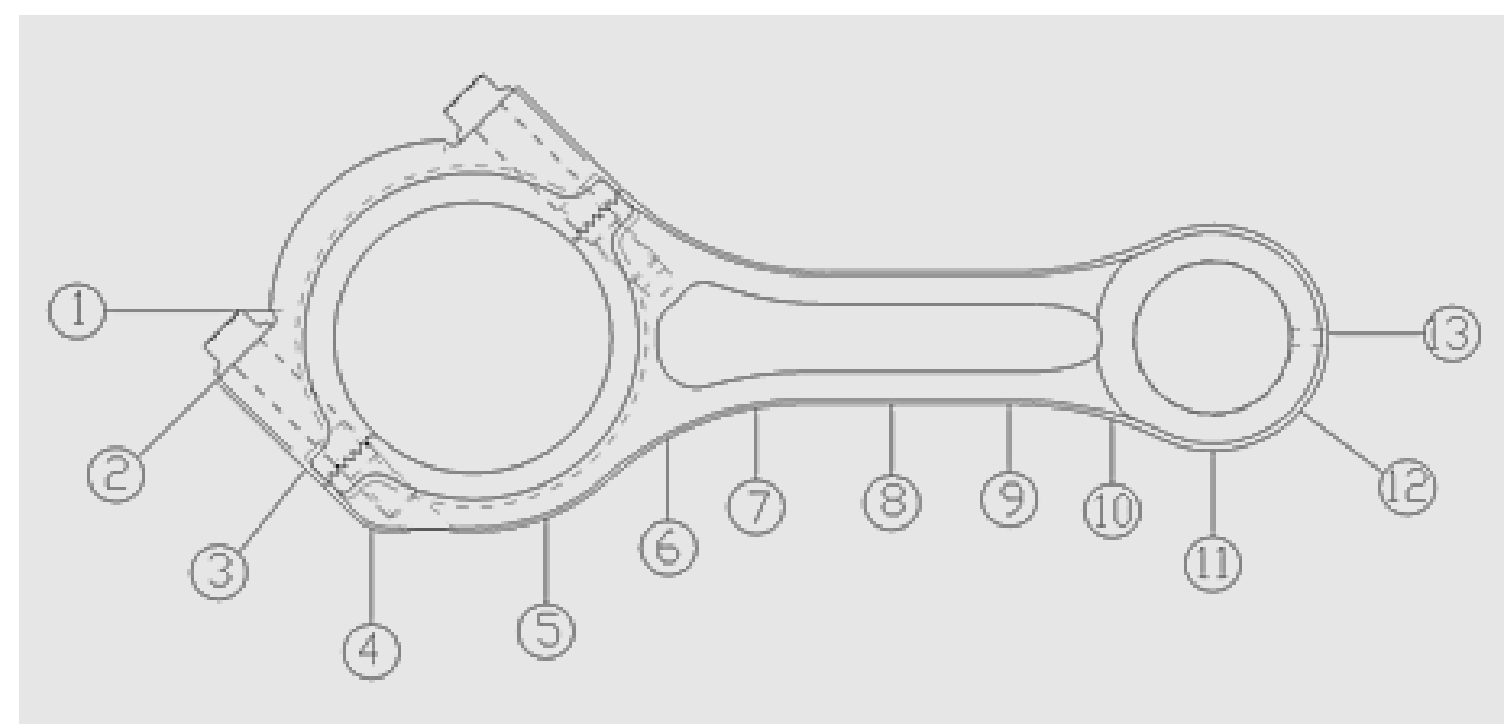

Fig.10. Different locations of connecting rod

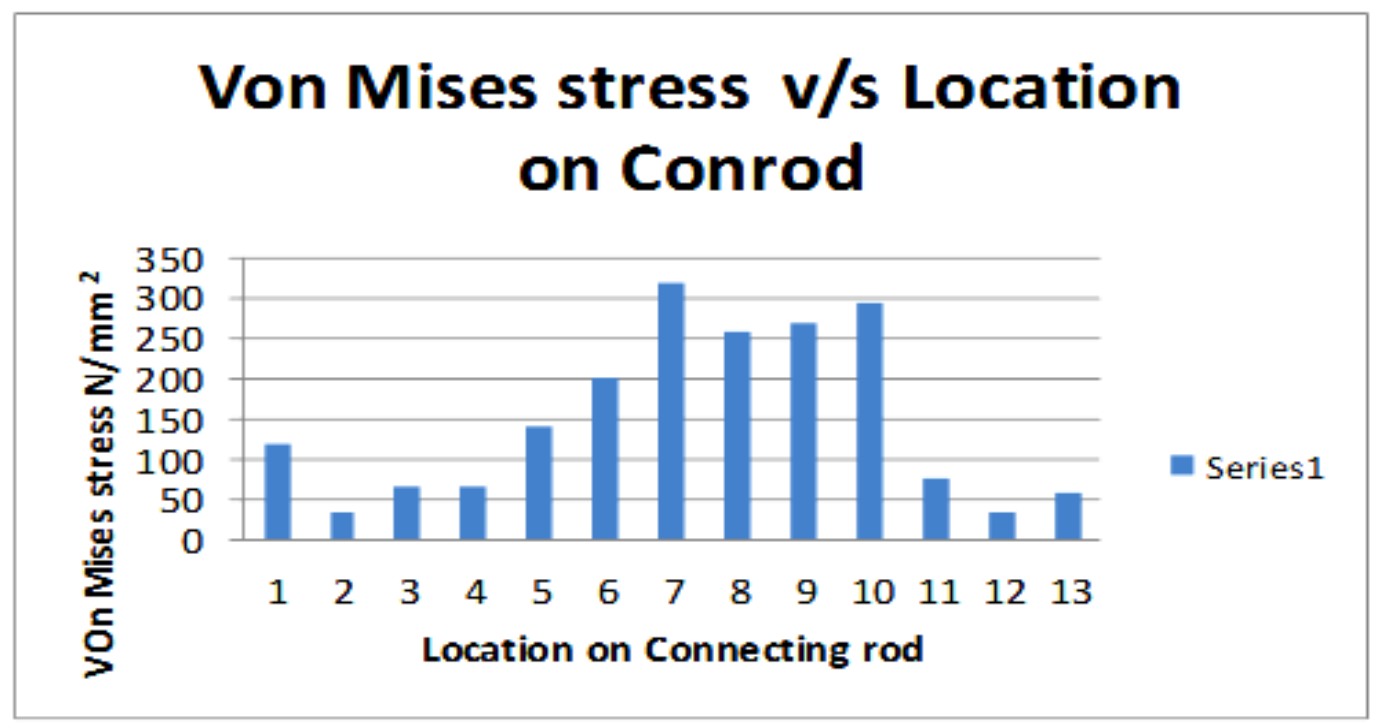

Fig.11. Von Mises stress at different locations of connecting rod 
International Journal of Design and Manufacturing Technology (IJDMT), ISSN 0976 - 6995(Print), ISSN 0976 - 7002(Online) Volume 5, Issue 1, January - April (2014), pp. 01-11 @ IAEME

\subsection{Weight Optimization of conrod}

There are many regions of the connecting rod where the stresses are much below the allowable stress values. In other words, the factor of safety is quite high in some of the portions of the connecting rod. These are locations 1 and 2 shown in figure 11 . These locations are near two ends of the connecting rod. These observations imply that there is potential for removing material from the regions with high factor of safety, resulting in weight reduction. Material can be removed from these regions in such a way that the overall functioning and assembly of the connecting rod is not affected. It must be also ensured that the stresses in these regions don't become so high that safety of the connecting rod compromised. It is desirable to reduce the weight of components of a mechanical system, especially if it is a moving component, as it results in saving in the material cost, and also the cost of energy required moving the component.

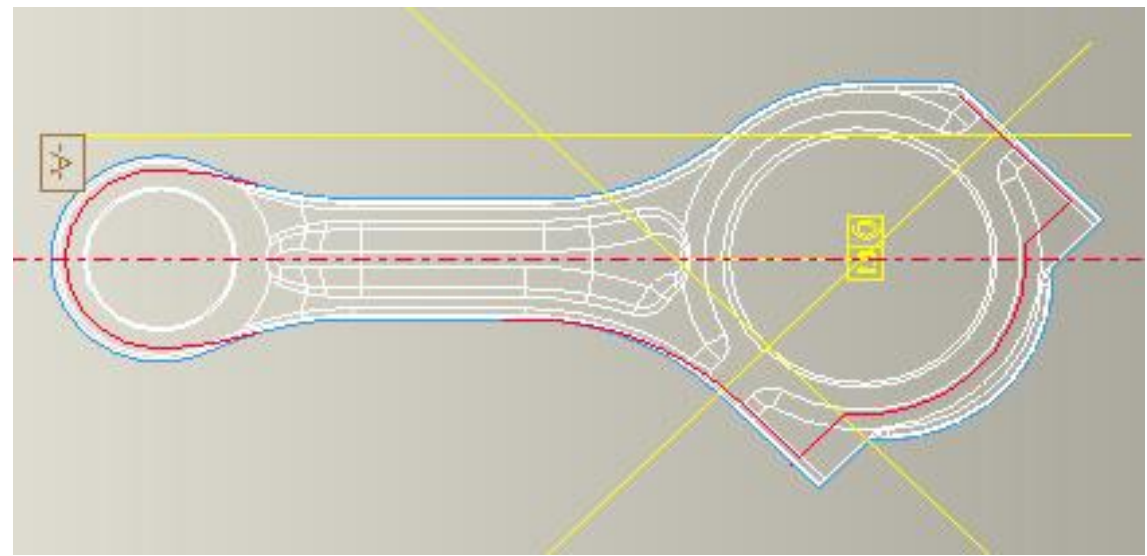

Fig.12. Blue lines are the original boundaries and red lines are the weight reduced boundary

These changes were implemented in the model and it was found that the resulting weight reduction was about $1 \mathrm{~kg}$, which is about $20 \%$. The modified connecting rod was then subjected stress analysis in the same way as original connecting These changes were implemented in the model and it was found that the resulting weight reduction was about 1 $\mathrm{kg}$, which is about $20 \%$. The modified connecting rod was then subjected stress analysis in the same way as original connecting rod.

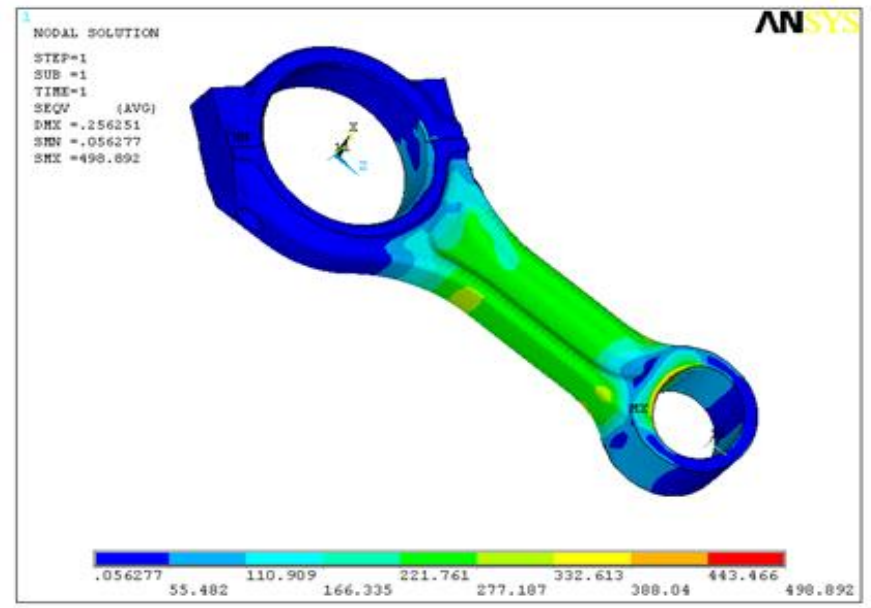

Fig.13. Stress Analysis Results, Modified Connecting Rod 
International Journal of Design and Manufacturing Technology (IJDMT), ISSN 0976 - 6995(Print), ISSN 0976 - 7002(Online) Volume 5, Issue 1, January - April (2014), pp. 01-11 @ IAEME

The modified conrod compressive, load on small end, big end fixed, maximum stress $=300 \mathrm{~N} / \mathrm{mm} 2$. Figures 13 to 14 show the FEA results for different cases of force application and boundary conditions. It can be seen from these figures that the stresses within the regions from which the material was removed, are somewhat higher, but still quite less. The maximum stresses remain almost the same as earlier which means that even with the removal of material, the connecting rod remains safe.

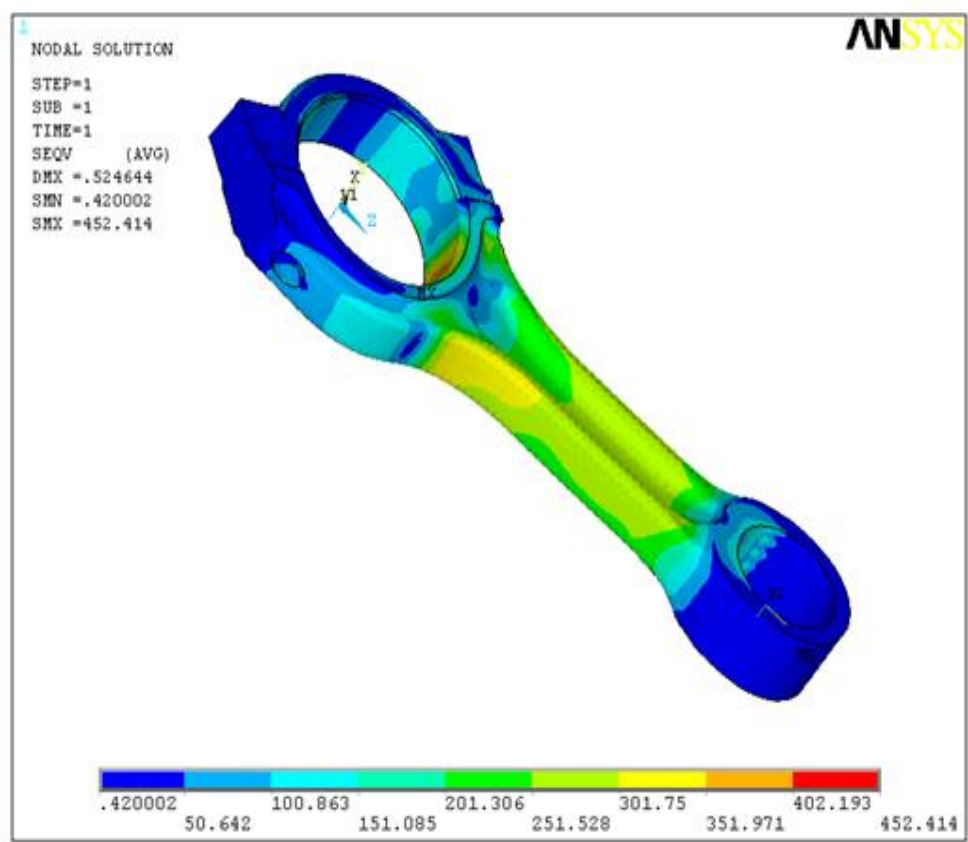

Fig.14. Stress analysis results, modified connecting rod

The compressive, load on big end, small end fixed, maximum stress $=320 \mathrm{~N} / \mathrm{mm} 2$. It can be seen that removal of material from those regions of the connecting rod, which are under less stress, can result in substantial weight reduction without compromising on the safety of the connecting rod. About $20 \%(1 \mathrm{~kg})$ reduction in mass of the connecting rod was achieved. This being a 16 cylinder engine, the total reduction in the mass of the connecting rods will be about $16 \mathrm{~kg}$, which is very substantial.

\section{CONCLUSION}

The constant speed engine conrod soft validation \& optimization is carried out using dynamic Load analysis method. The FEA results are used for optimization of conrod. The optimized design of this connecting rod was acceptable, because as the factor of safety for any crank angle location on connecting rod was higher than the endurance strength of forged steel used. The $20 \%$ reduction in weight, reduced the overall engine balancing requirement by $20 \%$ hence reduction in Vibration levels, better engine performance \& overall higher efficiency is achieved. 
International Journal of Design and Manufacturing Technology (IJDMT), ISSN 0976 - 6995(Print), ISSN 0976 - 7002(Online) Volume 5, Issue 1, January - April (2014), pp. 01-11 @ IAEME

\section{REFERENCES}

[1] Yoo, Y. M., Haug, E. J., And Choi, K. K., 1984, "Shape optimal design of AN ENGINE CONNECTING ROD," JOURNAL OF MECHANISMS, TRANSMISSIONS, AND Automation in Design, Transactions of ASME, Vol. 106, PP. 415-419.

[2] Serag, S., Sevien, L., Sheha, G., And El-Beshtawi, I.989, “Optimal Design of the CONNECTING-Rod”, Modelling, Simulation and Control, B, AMSE Press, Vol. 24, NO. 3, PP. 49-63.

[3] Sarihan, V. And Song, J., 1990 "Optimization of the Wrist Pin END of AN Automobile Engine Connecting Rod With an InTERFERENCE Fit," Journal of Mechanical Design, TRANSACtions of THE ASME, Vol. 112, PP. 406-412.

[4] PAI, C. L., 1996 "THE SHAPE OPTIMIZATION OF A CONNECTING ROD WITH FATIGUE LiFE COnstraint," Int. J. OF Materials And Product Technology, Vol. 11, No. 5-6, 1996, PP.

[5] Sonsino, C. M. And EsPer, F. J., "FATigue Design for PM CoMponents," European POWDER METALlurgy AsSOCiation (EPMA), 1994.

[6] Serag, S., Sevien, L., Sheha, G. and El-Beshtawi, I., 1989, "Optimal Design of THE CONNECTING-ROD”, MODELLING, SIMULATION AND CONTROL, B, AMSE PRESS, VOL. 24, NO. 3, PP. 49-63.

[7] G.V.S.S.SHARMA, DR.P.S.RAO, V.JAGADEESH AND AMIT VISHWAKARMA, "PROCESS CAPABILITY IMPROVEMENT - A CASE STUDY OF AN ENGINE CONNECTING ROD MANUFACTURING PROCESS", INTERNATIONAL JOURNAL OF MeChaniCAL ENGineERING \& TEChNOlOGY (IJMET), Volume 4, Issue 5, 2013, PP. 116 - 129, ISSN PRINT: 0976 - 6340, ISSN ONLINE: 0976 - 6359.

[8] SHYAMSUNDAR D. HIVARALE, PROF. DR. DILIP R. PANGAVHANE AND NITIN H. AMBHORE, "APPLICATION OF KNOWLEDGE ENGINEERING AND COMPUTATIONAL INTELLIGENCE FOR STRUCTURAL TOPOLOGY OPTIMIZATION OF FORGING CONNECTING ROD DIE”, INTERNATIONAL JOURNAL OF MECHANICAL ENGINEERING \& TECHNOLOGY (IJMET), VOLUME 4, ISSUE 2, 2013, PP. 10 - 20, ISSN PRINT: 0976 - 6340, ISSN ONLINE: 0976 - 6359.

[9] G.V.S.S.SHARMA, DR.P.S.RAO, V.JAGADEESH, AND AMIT VISHWAKARMA, "PROCESS CAPABILITY IMPROVEMENT - A CASE STUDY OF CRANK-PINBORE HONING OPERATION OF AN ENGINE CONNECTING ROD MANUFACTURING PROCESS" INTERNATIONAL JOURNAL OF ADVANCED RESEARCH IN ENGINEERING \& TECHNOLOGy (IJARET), Volume 4, IsSue 6, 2013, PP. 84 - 97, ISSN PRINT: 0976-6480, ISSN ONLINE: 0976-6499. 